\title{
Stenosis in gastric bypass for morbid obesity
}

Obesity is nowadays a first-rate healthcare issue. Metabolic syndrome, as developed by many patients with morbid or severe obesity secondary to hyperinsulinism, renders subjects at risk of cardiovascular disease. This, together with osteoarticular disease from overload, sleep apnea, and a long list of potential comorbidities, progressively impairs quality of life with a significantly reduced lifespan. Health resource use because of this condition has grown exponentially. The ineffectiveness of conservative therapy for obesity at this level has driven the development and implementation of various surgical techniques, which currently represent the therapeutic indication of choice. The incorporation of laparoscopy to this field has been a "second revolution", and dramatically increased surgical demand (1).

The use of laparoscopy with bariatric surgery strategies has changed the spectrum and presentation of post-operative complications (2). Thus, for instance, was the case with internal hernia, exceptional in open surgery, and with the condition reported by Campillo-Soto et al. (3) in this issue - stenotic gastro-jejunal anastomosis in laparoscopic gastric bypass (LGB). In LGB stenoses may develop at various levels: gastrojejunal anastomoses, which are most common; gastric pouch ring, when present, and jejuno-jejunal anastomosis at the Roux-en-Y. References to other locations exist on an exceptional basis (transverse mesocolon,...) (4).

\section{Gastrojejunal anastomosis stenosis}

Gastric bypass is a mixed technique with a restrictive, preferential effect, and an additional, malabsorptive action, even though this additional effect is currently considered to rather derive from digestive hormonal changes. Restriction is achieved by reducing gastric pouch size and reducing its outlet to facilitate rapid satiety. This latter factor may be achieved by placing a ring around the pouch or, more commonly, by performing a narrow gastrojejunal anastomosis. Should its diameter be excessively small or diminish by any cause stenosis would result, which is defined by symptoms, radiographic aspect, and endoscopic findings (5).

From a chronological viewpoint, a stenosis developing within the first six weeks may be secondary to anastomotic edema or occlusion by some retained clot (6). Between six and eight weeks factors such as scar retraction, anastomotic tension, etc., may develop and become apparent because of food texture changes (from purée to solid food) during this stage. From eight weeks on neomouth ulcers facilitated by non-steroidal anti-inflammatory drugs, alcohol or smoking add to suture ischemia and scar retraction as a cause of progressive dysphagia (7). 
Diagnostic suspicion is based on the upper obstructive symptoms patients report: nausea, vomiting, dysphagia, sialorrhea. Additionally, barium follow-through shows contrast sharpening and retention at the anastomosis (5). The inability to pass a standard 9.8-mm endoscope confirms the diagnosis (8). Szomstein et al. (9) performed endoscopies for symptoms suggestive of upper obstruction in 52 patients from a series of 535 gastric bypass procedures, and Gatrographin studies in 30 of them; they found a positive correlation between both findings.

Different technical factors may originate or facilitate stenosis development at the gastro-jejunal anastomosis, including suture type: manual, resorbable, monoplane or biplane, automatic circular or linear; tension at the anastomosis, blood supply, antecolic or retrocolic approach for the Roux-en-Y, ulcers at the anastomotic mouth (10), submucosal hematoma progressing to ischemic cicatricial fibrosis, anastomotic fistula healing (7), endoscopic hemostasia scleroses and their potential retraction, as mentioned by Campillo-Soto et al. (3).

In manual anastomosis non-absorbable sutures may facilitate ulcer development, as well as bezoar development. Biplane suture is more susceptible to ischemia, and reduces the lumen because of its inherent invagination. Continuous, tension-knotted suture may reduce the anastomotic perimeter when a calibrating probe is not used (7). Vasquez et al. (11) report fewer complications at the gastro-jejunal anastomosis in their series of 315 gastric bypasses when the reinforcing suture applied on the 25$\mathrm{mm}$ circular stapling is made out of resorbable thread. Ruiz de Adana et al. (12), in their prospective cohort study on 242 LGB procedures with manual anastomosis, obtained $9.5 \%$ of stenosis in the gastro-jejunal anastomoses with resorbable multifilament suture, and $0.7 \%$ in the group receiving resorbable monofilament thread.

In mechanical anastomoses circular staplers seem to result in greater scar retraction, particularly those with a smaller caliber $(21 \mathrm{~mm})$. Campillo-Soto et al. (3) present $8.1 \%$ of stenoses with 21 -mm staplers. In the study by Suggs et al. (13) in 438 patients, LGBs performed with a $25-\mathrm{mm}$ stapler had $2.9 \%$ stenoses as compared to $9.4 \%$ with $21-\mathrm{mm}$ staplers. Fischer et al. (14), in a prospective randomized, blind study of 200 patients comparing both diameters found $17 \%$ stenoses with $21-\mathrm{mm}$ and $7 \%$ with 25 -mm staplers. However, Frutos et al. (15), in 676 LGBs with anastomoses performed with $21-\mathrm{mm}$ staplers reported $3.4 \%$ stenoses. Bleeding also seems more common, which prompt endoscopic scleroses (3). In this respect, linear staplers have the advantage that intraluminal stapling may be inspected before anastomosis completion. Our own experience with 1,271 gastro-jejunal anastomoses with linear stapler for band LGB is $2.3 \%$ of stenoses, whereas Carrodeguas et al. (16), in 1,291 patients with linear anastomosis, recorded stenoses in $7.3 \%$.

At the time of switching from liquid or doughy to solid food, which is usually recommended between four and six weeks following surgery, patients start to notice passage difficulties. On occasion it presents with food impaction requiring urgent endoscopy, where a stenosis is revealed. Obstructive symptoms in this initial stage may be due to deficient mastication or anastomotic edema, and spontaneously resolve within up to two weeks. A proton pump inhibitor (PPI) at $80 \mathrm{mg} / \mathrm{day}$, nonsteroidal anti-inflammatory drugs, and/or parenteral corticoids, in addition to an antiemetic, are useful in this condition according to Campos et al. (7). Therapy with a PPI also benefits stenosis associated with neomouth or marginal ulcer prior to dilation.

The treatment of choice of stenosis is balloon dilation. The use of SavaryGilliard dilators is rejected by many authors given the risk of perforation, since the loop may be on a different axis as compared to the anastomosis, and because, if distally advanced, may result in anastomosis dehiscence (7). However, Fernández-Es- 
parrach et al. (17) provide good results after dilating 24 gastro-jejunal anastomotic stenoses with these plugs.

Commonly used balloons include the TTS (through the scope) type, which are preferentially filled with serum up to a maximum diameter of $15 \mathrm{~mm}$ (18), under the control of a manometer correlating pressure with diameter. This tools exerts a radial pressure that reduces the risk of fistula from anastomosis rupture. The use of diameters in excess of $20 \mathrm{~mm}$ may result in weight gain, a risk not unknown for smaller calibers, particularly when the stenoses are long-term and the patient has become accustomed to "liquid calories". Swartz et al. (19), in a study of 204 stenoses, suggest adapting dilation diameter to stenosis extent; $12 \mathrm{~mm}$ for low grade, $13.5 \mathrm{~mm}$ for mid grade, and $15 \mathrm{~mm}$ for high grade.

A single dilation procedure usually suffices. Should stenosis relapse after two or three sessions, its sectioning into two, three or four quadrants using an endoscopic scalpel may be considered. Surgical treatment is reserved for cases resistant to endoscopic therapy, with a high risk for surgical complications, or in the absence of adequate tools or equipment (7).

\section{Cerclage stenosis}

To keep the gastric pouch outlet caliber constant regardless of gastrojejunal anastomosis issues some surgeons use cerclages around it. These may consist of silicone tubing, polypropylene mesh or other materials (expanded polytetrafluoroethylene, PTFE). Stenoses with various causes may also develop at this level: excessive tension when placed, sliding, hardening and retraction, erosion, inclusion in the gastric pouch lumen, or fibrous capsule formation. In our series of 1,271 patients undergoing band LGB, 4 of 17 receiving silicone tubing cerclage developed stenosis and required cerclage withdrawal; no stenoses were seen in those receiving propylene mesh cerclage $(6.5 \mathrm{~cm}$ in circumference). In these patients cerclage opening may be attempted with endoscopic dilations by breaking closing sutures, but this is commonly of no use and withdrawal is needed. When in the lumen, silicone or PTFE cerclages may be withdrawn with endoscopy, with a variable difficulty. For propylene mesh symptoms will improve by sectioning and withdrawing the portions exposed within the gastric pouch via repeat endoscopy procedures (7), but their complete extraction is highly unlikely with this method; a surgical procedure may be required.

\section{Jejunojejunal stenosis anastomosis}

In the anastomosis at the base of the Roux loop, the narrowing usually results from a technical error in the procedure. This anastomosis may support severe stenosis since it is only fluid that flows through it (gastric juice, bile, pancreatic juice). It is the most common cause of partial obstruction in the early small bowel. Computerized tomography is the most reliable diagnostic tool, and surgery the most appropriate, definite treatment (20). The situation may become critical when bleeding occurs, since clots may result in obstruction. In such a case it manifests in the immediate postoperative period as distension in the Roux-en-Y afferent loop (biliopancreatic loop) with acute gastric dilation. Urgent gastric decompression and gastrostomy placement are required, as well as a reconstruction of the jejunojejunal anastomosis.

In summary, stenosis is a relatively common complication of gastric bypass. Causes of gastrojejunal anastomosis stenosis are multiple and literature references 
are conflicting regarding incidence and etiological factors, particularly with respect to the anastomotic technique. The treatment of choice is pneumatic dilation, which is usually effective.

\section{F. de-la-Cruz-Vigo ${ }^{1}$ and J. L. de-la-Cruz-Vigo ${ }^{2}$}

${ }^{\prime}$ Service of General and Digestive Surgery "A”. University Hospital 12 de Octubre. Madrid, Spain. ${ }^{2}$ Unit of Laparoscopic Surgery. Clínica San Francisco. León, Spain

\section{REFERENCES}

1. Cruz Vigo F, Cruz Vigo JL. La obesidad: problema del siglo XXI. En: Cruz Vigo F, Cruz Vigo JL, editores. Bypass gástrico por laparoscopia. Cáceres: Centro de Cirugía de Mínima Invasión; 2005. p. 21-33.

2. Smith SC, Edwards CB, Goodman GN, Halversen RC, Simper SC. Open vs laparoscopic Roux-en-Y gastric bypass: comparison of operative morbidity and mortality. Obes Surg 2004; 14(1): 73-6.

3. Campillo-Soto A, Torralba-Martínez JA, Martín-Lorenzo JG, Lirón-Ruiz R, Bento-Gerard M, Pérez-Cuadrado E, et al. Gastrojejunal anastomosis stricture after laparoscopic gastric bypass. Our experience with 62 patients. Rev Esp Enferm Dig 2010; 102(3): 187-92.

4. Ahmed AR, Rickards G, Messing S, Husain S, Johnson J, Boss T, et al. Roux limb obstruction secondary to constriction at transverse mesocolon rent after laparoscopic Roux-en-Y gastric bypass. Surg Obes Relat Dis 2009; 5(2): 194-8.

5. Garrido T, Maluf Filho F, Sakai P. O papel da endoscopia na cirurgia bariátrica. En: Garrido Jr. AB, Ferraz EM, Barroso FL, Marchesini JB, Szego T, editors. Cirurgia da obesidade. Sao Paulo: Ed. Atheneu; 2003. p. 293-302.

6. Wetter A. Role of endoscopy after Roux-en-Y gastric bypass surgery. Gastrointest Endosc 2007; 66(2): 2535 .

7. Campos JM, Ferreira Filho HA, Galvao Neto MP, Falcao M, Jeronimo da Silva CE. Estenosis de la anastomosis gastroyeyunal. En: Campos JM, Galvao Neto MP, Moura EGH, editores. Endoscopia en cirugía de la obesidad. Caracas: Amolca; 2009. p. 215-27.

8. Huang CS, Farraye FA. Endoscopy in the bariatric surgical patient. Gastroenterol Clin North Am 2005; 34(1): 151-66.

9. Szomstein S, Kaidar-Person O, Naberezny K, Cruz-Correa M, Rosenthal R. Correlation of radiographic and endoscopic evaluation of gastrojejunal anastomosis after Roux-en-Y gastric bypass. Surg Obes Relat Dis 2006; 2(6): 617-21

10. Cruz Vigo JL, Cruz Vigo F, Sanz de la Morena P, Canga Presa JM, Martínez Pueyo JI. Consideraciones técnicas para minimizar las complicaciones. Cir Esp 2004; 75(5): 292-8.

11. Vasquez JC, Wayne Overby D, Farrell TM. Fewer gastrojejunostomy strictures and marginal ulcers with absorbable suture. Surg Endosc 2009; 23(9): 2011-5.

12. Ruiz de Adana JC, Hernández Matías A, Hernández Bartolomé M, Manzanedo Romero I, León Ledesma R, Valle Rubio A, et al. Risk of gastrojejunal anastomotic stricture with multifilament an monofilament sutures after hand-sewn laparoscopic gastric bypass: a prospective cohort study. Obes Surg 2009; 19(9): 1274-7.

13. Suggs WJ, Kouli W, Lupovici M, Chau WY, Brolin RE. Complications at gastrojejunostomy after laparoscopic Roux-en-Y gastric bypass: comparison between 21- and 25-mm circular staplers. Surg Obes Relat Dis 2007; 3(5): 508-14.

14. Fischer BL, Atkinson JD, Cottam D. Incidence of gastroenterostomy stenosis in laparoscopic Roux-en-Y gastric bypass using 21- or 25-mm circular stapler: a randomized prospective blinded study. Surg Obes Relat Dis 2007; 3(2): 176-9.

15. Frutos MD, Luján J, García A, Hernández Q, Valero G, Gil J, Parrilla P. Gastrojejunal anastomotic stenosis in laparoscopic gastric bypass with a circular stapler $(21 \mathrm{~mm})$ : incidence, treatment and long term follow-up. Obes Surg 2009; 19(12): 1631-5.

16. Carrodeguas L, Szomstein S, Zundel N, Lo Menzo E, Rosenthal R. Gastrojejunal anastomotic strictures following laparoscopic Roux-en-Y gastric bypass surgery: analysis of 1291 patients. Surg Obes Relat Dis 2006; 2(2): 92-7.

17. Fernández-Esparrach G, Bordas JM, Llach J, Lacy A, Delgado S, Vidal J, et al. Endoscopic dilation with Savary-Gilliard bougies of stomal strictures after laparoscopic gastric bypass in morbidly obese patients. Obes Surg 2008; 18(2): 155-61.

18. Peifer KJ, Shiels AJ, Azar R, Rivera RE, Eagon JC, Jonnalagadda S. Successful endoscopic management of gastrojejunal anastomotic strictures after Roux-en-Y gastric bypass. Gastrointest Endosc 2007; 66(2): 24852 .

19. Swartz DE, Gonzalez V, Felix EL. Anastomotic stenosis after Roux-en-Y gastric bypass: A rational approach to treatment. Surg Obes Relat Dis 2006; 2(6): 632-6.

20. Cho M, Carrodeguas L, Pinto D, Lascano C, Soto F, Whipple O, et al. Diagnosis and management of partial small bowel obstruction after laparoscopic antecolic antegastric Roux-en-Y gastric bypass for morbid obesity. J Am Coll Surg 2006; 202(2): 262-8. 